CLINICAL STUDY

\title{
Nodular disease and parafollicular C-cell distribution: results from a prospective and retrospective clinico-pathological study on the thyroid isthmus
}

\author{
Giampaolo Papi ${ }^{1,4}$, Giulio Rossi ${ }^{2}$, Salvatore Maria Corsello ${ }^{1}$, Stefania Corrado ${ }^{2}$, Guido Fadda ${ }^{3}$, Carlo Di Donato ${ }^{4}$ \\ and Alfredo Pontecorvi ${ }^{3}$ \\ ${ }^{1}$ Chair of Endocrinology, Catholic University of Rome, Rome, Italy, ${ }^{2}$ Institute of Pathology, University of Modena and Reggio Emilia, Modena, Italy, \\ ${ }^{3}$ Institute of Anatomic Pathology, Catholic University of Rome, Rome, Italy and ${ }^{4}$ Department of Internal Medicine, Azienda USL of Modena, Ospedale \\ 'Ramazzini', Via S Giacomo 2, 41012 Carpi, Modena, Italy \\ (Correspondence should be addressed to G Papi at Dipartimento di Medicina Interna, Azienda USL of Modena; Email: papigiampaolo@hotmail.com)
}

\begin{abstract}
Objective: The isthmus represents a peculiar, as yet partially unexplored, thyroid gland area. Aim of the study: To assess i) the prevalence and clinico-pathological features of solitary thyroid isthmic nodules (STIN); ii) the frequency of medullary thyroid carcinoma (MTC) arising from the isthmus; and iii) the C-cell distribution in the isthmus of patients with MTC and benign nodular thyroid disease (NTD).

Subjects and methods: Patients referred from 2006 to 2008 for STIN were prospectively recruited, and underwent serum calcitonin $\left(C_{t}\right)$ measurement and fine needle aspiration cytology (FNAC). MTCs diagnosed from 1993 to 2005 were retrospectively searched. Immunohistochemistry was performed using anti- $C_{t}$ antibodies on lateral lobes and isthmi of 50 benign NTD and 50 MTC cases.

Results: From 1993 to 2005, 150 patients underwent surgery for MTC. All patients had the neoplasm located in lateral thyroid lobes, none in the isthmus. In the 3 years following, 192 STIN patients (40 (21\%) males, 152 (79\%) females; mean age: $46.2 \pm 7.1$ years; $6.4 \%$ of NTD subjects) were recruited. All had normal $C_{\mathrm{t}}$ concentrations. FNAC was malignant or suspicious for malignancy in $14(7.3 \%)$ patients. Histology found malignancy in $17(9 \%)$ cases, MTC in none. C cells were disclosed in lateral thyroid lobes of $100 \%$ MTC and $77 \%$ benign NTD patients; isthmi were free of C cells in either group.

Conclusions: STINs are significantly less likely to be MTC in patients presenting with sporadic disease. Therefore, $C_{\mathrm{t}}$ screening is not warranted in these subjects. Nonetheless, STINs are more likely to be neoplastic and deserve equal attention as those of the lateral lobes.
\end{abstract}

European Journal of Endocrinology 162 137-143

\section{Introduction}

Nodular thyroid disease (NTD) is frequently observed in the clinical practice (1). Indeed, on thyroid ultrasound, NTD prevalence approaches $50 \%$ in iodine-deficient areas (2). Fortunately, malignant neoplasm is rarely seen, accounting for $5 \%$ or less of thyroid nodules $(1,2)$. Medullary thyroid carcinoma (MTC) is a neuroendocrine tumor, regarded as the most aggressive of welldifferentiated thyroid carcinomas, with a survival rate of $50 \%$ at 10 years (3). MTC arises from parafollicular C cells, which are responsible for both the production and the release of calcitonin $\left(C_{\mathrm{t}}\right)$, a peptide hormone (4). MTC is sporadic in about $75 \%$ of the cases, whereas its familial counterpart - isolated or in the context of MEN type 2 syndrome - accounts for the remainder of the cases (5).
Several studies (6-12) on sporadic MTC have demonstrated that the earlier the diagnosis the better the prognosis of MTC. $C_{\mathrm{t}}$ has been shown to represent a sensitive marker for MTC, leading to the early diagnosis of the neoplasm even when fine needle aspiration cytology (FNAC) discloses benign features (as occurs in nodules smaller than $10 \mathrm{~mm}$ ).

Based on such evidence, the European Thyroid Association (ETA), developing the guidelines for the management of differentiated thyroid carcinoma (13), recommended the use of $C_{\mathrm{t}}$ screening in all patients with thyroid nodule(s). In 2006, the American Thyroid Association (ATA) published its guidelines addressing thyroid nodules (14), where $C_{\mathrm{t}}$ screening was not recommended due to its low specificity, the high prevalence of thyroid nodules in the general population, the rarity of MTC, and the costs of the test. In June 2009, the ATA 
had published specific guidelines for the diagnosis and the management of MTC (15) and, again, although recent studies from the United States have confirmed the European observations and cost-effectiveness of the test (16), $C_{\mathrm{t}}$ screening was not recommended.

Immunohistochemical studies $(17,18)$ conducted in autopsy series from 1990s failed to demonstrate any evidence of $\mathrm{C}$ cells in the isthmus of normal thyroid glands. Similarly, no C cells were detected at immunohistochemical examination in the isthmi of patients who underwent total thyroidectomy for MTC or C-cell hyperplasia (CCH) (19).

To the best of our knowledge, no studies - either retrospective or prospective - have been conducted so far to assess both prevalence and clinico-pathological features of solitary thyroid isthmic nodules (STIN). Based on the hypothesis that in the absence of $\mathrm{C}$ cells in the thyroid isthmus MTC should not occur, the present study was designed to answer the following questions: what are prevalence and clinico-pathological features of STIN? What is the frequency of MTC in patients with STIN? What is the distribution of parafollicular C cells in the thyroid of subjects with MTC and benign NTD?

\section{Patients and methods}

\section{Aim of the study}

The aim of the present study was to assess i) the prevalence and clinico-pathological features of STINs; ii) the frequency of MTC in STIN; and iii) C-cell distribution in the isthmus of patients with MTC and benign NTD.

\section{Study design}

To assess the prevalence and clinico-pathological characteristics of STIN, a 3-year prospective study was conducted, whereas to evaluate the frequency of MTC in patients with STIN, both a retrospective and a prospective study were performed.

i) Retrospective study. A database research having 'MTC' and 'histology' as keywords, and spanning the period from January 1993 to December 2005, was made from the files of the sections of Pathology of both the Catholic University of Rome and the University of Modena and Reggio Emilia, Italy. Once MTC cases were selected, the following data were retrospectively sought: age, sex, the neoplasm origin (sporadic or hereditary), and the location of the neoplasm within the thyroid gland.

ii) Prospective study. During the period from January 1, 2006 to December 31, 2008, 4723 consecutive patients with suspected NTD were referred to the Division of Endocrinology, 'A. Gemelli' Hospital - Catholic University of Rome, and to the
Endocrine Outpatient Clinics of 'Ramazzini' Hospital - Azienda USL of Modena, Italy. Inclusion criteria were a) male and female patients; b) solitary palpable nodule of the thyroid isthmus; c) solitary nonpalpable nodule of the thyroid isthmus $\geq 10 \mathrm{~mm}$ in its largest diameter; d) solitary nonpalpable isthmic nodule smaller than $10 \mathrm{~mm}$, showing ultrasound features suspicious for malignancy (microcalcifications, undefined margins, and intra-nodular vascularization). Exclusion criteria were a) the presence of multiple thyroid nodules; b) solitary thyroid nodules affecting the lateral lobes (including those located in the boundary zones between the lateral thyroid lobes and the isthmus); c) nonpalpable isthmic nodule smaller than $10 \mathrm{~mm}$ lacking ultrasound features suspicious for malignancy; d) patients previously evaluated for nodular goiter by FNAC and/or $C_{\mathrm{t}}$ measurement; e) patients reporting a family history of MEN and those previously thyroidectomized for sporadic MTC; f) patients with hyper- and hypothyroidism without nodules; g) patients in follow-up for thyroid diseases; and h) patients not confirmed to have thyroid diseases.

To evaluate the distribution of parafollicular $\mathrm{C}$ cells in the thyroid glands of subjects with either MTC or benign NTD, 50 consecutive cases of MTC (both familial and sporadic) found through the retrospective database research and 50 cases of nodular goiter consecutively diagnosed after total thyroidectomy during the 3-year prospective study were selected.

\section{Patients}

During the 12-year period of the retrospective study, 21288 thyroidectomies were performed in our institutions.

During the 3-year period of the prospective study, 3978 patients with thyroid nodules were evaluated at our institutions. Of these, $256(6.4 \%)$ presented with a solitary nodule of the thyroid isthmus. In total, 222 patients fulfilled the criteria of the study design but 30 dropped out of the study either because they refused FNAC and/or surgery $(n=8)$ or because they were lost to follow-up after the first visit $(n=22)$. Of the remaining 192 patients, 111 (58\%) were recruited by the Institute of Endocrinology of the Catholic University of Rome, and $81(42 \%)$ were recruited by the Endocrine Outpatient Unit of 'Ramazzini' Hospital of AUSL Modena. When matched for gender, age, $C_{\mathrm{t}}$, and TSH concentrations, no significant differences were found among the patients recruited by the two different institutions.

All patients satisfying the inclusion criteria underwent the following procedures: a) blood sample for the measurement of serum TSH and $C_{\mathrm{t}}$ concentrations and b) ultrasound-guided FNAC. 
When the TSH value was abnormal, serum-free thyroxine $\left(\mathrm{FT}_{4}\right)$ and free triiodothyronine concentrations were also measured. Furthermore, patients with suppressed serum TSH concentrations underwent ${ }^{99} \mathrm{~m}$ Technetium-thyroid scan, to detect autonomously functioning nodules.

Surgery was always recommended if one of the following criteria was met: a) FNAC diagnostic or suspicious for malignancy (indeterminate included); b) repeated $(>2)$ nondiagnostic FNACs; and c) complaints of compressive symptoms (dysphagia and dyspnea). All patients gave informed consent to the diagnostic and therapeutic procedures.

\section{Methods}

CT assay Serum $C_{\mathrm{t}}$ concentrations were measured in the laboratories of the institutions involved in the study, using the same two-site chemiluminescence immunoassay (immunoluminometric assay, Nichols Institute Diagnostics, San Juan Capristano, CA 92675, USA).

Ultrasound and fine needle aspiration biopsy Thyroid ultrasound was performed utilizing a Philips En Visor C machine (Philips Medical Systems SpA, Monza, MI, Italy). Ultrasound-guided fine needle aspiration biopsy was performed on nodular areas with 23-27 gauge needles, using a 7.5-13 MHz probe. Multiple direct smears were prepared, and May-Grunwald-Giemsa and Papanicolau stainings were employed.

Surgery Patients recruited in the 3-year prospective study design with a benign FNAC and compressive symptoms underwent isthmusectomy. In case of a suspicious or repeatedly nondiagnostic FNAC, frozen sections of the nodule(s) were obtained for intraoperative histological examination to decide the definitive surgical extension. In all patients undergoing surgery following a cytological diagnosis of malignancy, total thyroidectomy was the procedure of choice completed by a lymphadenectomy in case of lymph node involvement.

Histological and immunohistochemical examination of surgical specimens Given that isthmus has no standard size (20), in this study isthmic region was considered as the thyroid tissue interposed between the two lateral lobes.

MTC cases found through the retrospective 12-year database research were all reviewed.

In the 100 cases of total thyroidectomy selected to identify the presence of $\mathrm{C}$ cells throughout the isthmi and the lateral thyroid lobes, microscopic slides were obtained by three formalin-fixed and paraffin-embedded $5 \mathrm{~mm}$ large specimens of thyroid tissue devoid of nodules: one derived from the middle of the isthmus, one from the middle of the right thyroid lobe, and one from the middle of the left thyroid lobe. Immunohistochemical studies were performed on such tissues by means of an automated immunostainer (Benchmark, Ventana, Tucson, AZ, USA) using antibodies directed against $C_{\mathrm{t}}$ (polyclonal: Ventana; microwave antigen retrieval). $\mathrm{CCH}$ was defined as the presence of more than $50 \mathrm{C}$ cells in a single low-power field $(\times 10$ magnification) in both thyroid lobes (21), of solid nests of C cells with $>7$ cells per nest, or of follicles completely surrounded by $\mathrm{C}$ cells.

\section{Statistical analysis}

Results are reported as mean \pm s.D. All statistics were conducted using the commercially available software program SPSS for Windows, release 10.0 (SPSS Inc., Chicago, IL, USA).

\section{Results \\ Retrospective study}

Of 21288 cases of thyroidectomy performed in our institutions in the period from January 1993 to December 2005, 150 (0.7\%) MTCs were discovered: 126 of the sporadic form and 24 of the hereditary form (nine with familial MTC (FMTC) and 15 with MEN 2A). The diagnosis of MTC was confirmed by our pathologists in all the 150 cases. Sixty-five $(43.3 \%)$ patients were males, $85(56.7 \%)$ were females, with a female to male ratio of 1.3 to 1 , ranging in age from 9 to 83 years (mean: $55.2 \pm 7.2$ years; median: 59 years). The results of cytological examination before surgery are reported in Table 1. The neoplasm was located within the right lateral lobe of the thyroid gland in $84(56 \%)$ cases and in the left lateral lobe in $66(44 \%)$ cases; it was detected in the thyroid isthmus in none of the cases.

\section{Prospective study}

Of 192 subjects with solitary isthmic nodule recruited in the study, $40(21 \%)$ were males and $152(79 \%)$ were females, with a female-to-male ratio of 3.8 to 1 .

Table 1 Results of fine needle aspiration cytology in 150 patients with medullary thyroid carcinoma.

\begin{tabular}{lc}
\hline & Cytological examination \\
\hline Repeatedly nondiagnostic & 0 \\
Benign & 21 \\
Indeterminate & 11 \\
Suspicious for malignancy & 40 \\
Malignant & 74 \\
Not performed & 4 \\
Total & 150 \\
\hline
\end{tabular}


Table 2 Results of fine needle aspiration cytology (FNAC) in 192 patients with solitary isthmic nodules and consequent treatment.

\begin{tabular}{lccccc}
\hline & $\begin{array}{c}\text { Repeatedly } \\
\text { nondiagnostic }\end{array}$ & Benign & Indeterminate & $\begin{array}{c}\text { Suspicious for } \\
\text { malignancy }\end{array}$ & $\begin{array}{c}\text { Malignant } \\
\text { Total }\end{array}$ \\
Submitted to surgery & $2(1.1 \%)$ & $171(89.1 \%)$ & $5(2.6 \%)$ & $7(3.6 \%)$ & $7(3.6 \%)$ \\
Treated by TSH-suppressive therapy & 2 & 27 & 5 & 7 & 7 \\
Followed without therapy & 0 & 31 & 0 & 0 & 0 \\
\hline
\end{tabular}

FNAC, fine needle aspiration cytology; TSH, thyrotropin.

The mean age was $46.2 \pm 7.1$ years (range: $21-84$ years; median: 49 years). Mean serum TSH concentrations were $3.7 \pm 2.3 \mathrm{mIU} / \mathrm{l}$. One hundred and eightysix patients $(97 \%)$ were euthyroid, four patients $(2 \%)$ were hypothyroid (three with subclinical and one with overt hypothyroidism) due to Hashimoto's thyroiditis, and two patients $(1 \%)$ were overtly hyperthyroid due to Graves' disease. Mean serum $C_{\mathrm{t}}$ concentrations were $2.2 \pm 0.4 \mathrm{pg} / \mathrm{ml}$ and were normal in all 192 patients. Thyroid ultrasound detected hypoechoic nodules in 156 patients $(81 \%)$, isoechoic nodules in $27(14 \%)$, and hyperechoic nodules in $9(5 \%)$. The mean diameter of isthmic nodules was $29.5 \pm 8 \mathrm{~mm}$ (range: $8-52 \mathrm{~mm}$ ). The results of cytological examination are reported in Table 2. Fourteen $(7.3 \%)$ nodules harbored cytological features suspicious for or consistent with papillary thyroid carcinoma (PTC). In no case was a cytological diagnosis of MTC given. In total, 113 subjects were followed up with observation only, 31 (with cytological diagnosis of 'benign colloid nodule') were treated by $\mathrm{L}-\mathrm{T}_{4}$ TSH-suppressive therapy, 48 underwent thyroidectomy (total thyroidectomy in 26 cases and isthmusectomy in 22 cases) (Table 2). Histological examination demonstrated a benign nodule in 31 cases and a malignant neoplasm in $17(9 \%)$ cases. Of the 17 cases diagnosed with malignancy, 16 were PTCs (of which, eight $(50 \%)$ were smaller than $10 \mathrm{~mm}$ in their largest diameter), and one was a follicular carcinoma. In no case was there evidence of a MTC.

\section{Immunohistochemical study}

In Fig. 1, the results of immunohistochemical study are reported.

A positive reaction to $C_{\mathrm{t}}$ immunostaining was observed in the lateral thyroid lobes of all $50(100 \%)$ patients with both sporadic and hereditary MTC. CCH (Fig. 2A) was demonstrated in 14 out of $14(100 \%)$ patients affected by hereditary MTC (FMTC or MEN2A), and in 26 out of $36(72 \%)$ subjects with sporadic MTC. On the contrary, no $C_{\mathrm{t}}$-positive cells were seen in the isthmi of either group (Fig. 2B). Similarly, in 38 out of $50(76 \%)$ patients with benign NTD, $C_{t}$ reaction was positive within the lateral thyroid lobes; however, contrary to the picture found in MTC patients, in these benign NTD cases, $\mathrm{C}$ cells appeared as sparse or even isolated (Fig. 2C) and $\mathrm{CCH}$ criteria were never met. Again, no $C_{\mathrm{t}}$-positive cells were found in the isthmi of this patient group (Fig. 2D).

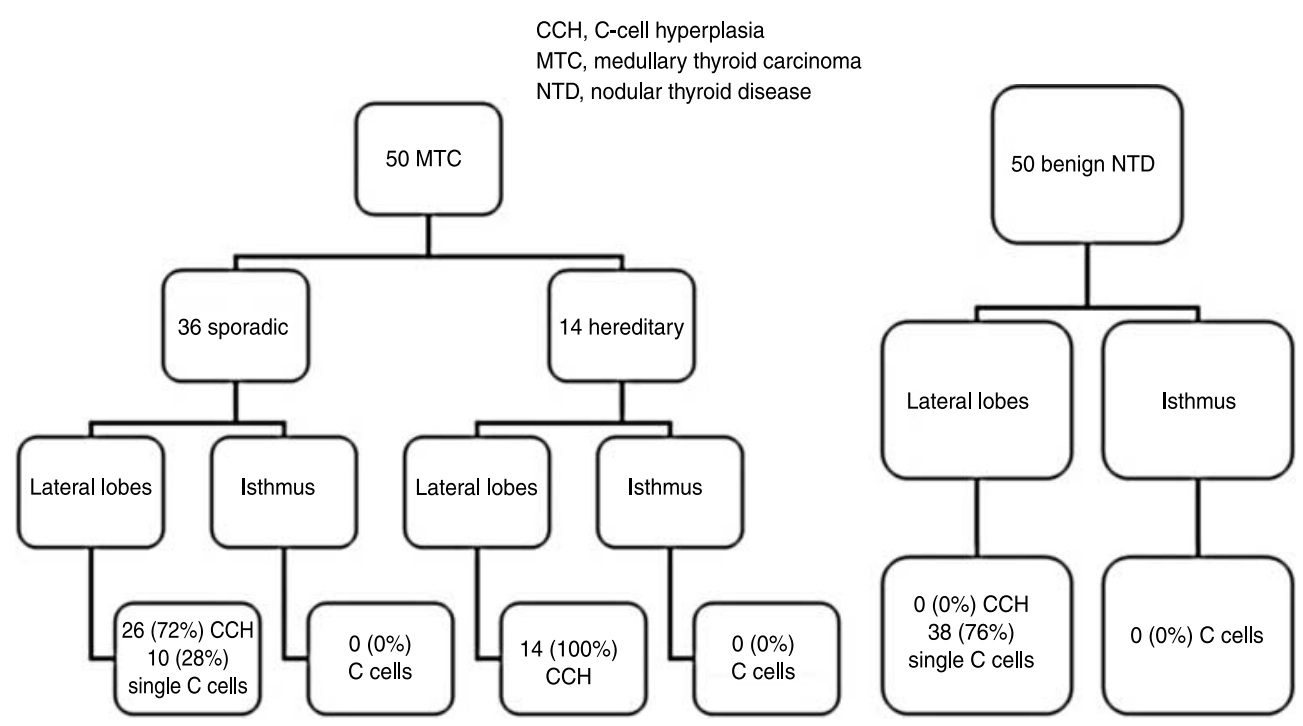

Figure 1 Summary of immunohistochemical examination results in 50 patients with medullary thyroid carcinoma (MTC) and 50 patients with benign nodular thyroid disease (NTD). 

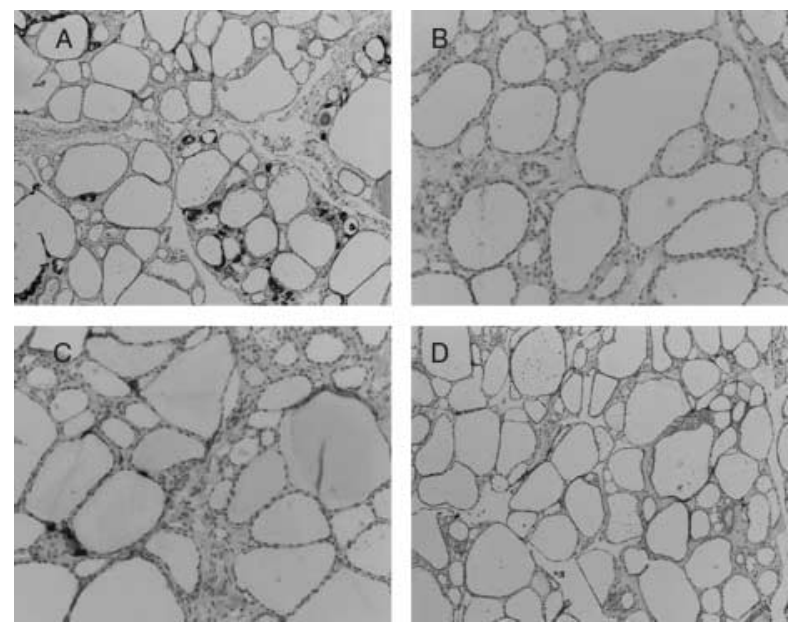

Figure 2 Results of immunohistochemical examination using antibodies against calcitonin $\left(C_{\mathrm{t}}-\mathrm{Ab}\right)$. (A) C-cell hyperplasia in the lateral thyroid lobe of a patient with medullary thyroid carcinoma (MTC) $\left(C_{\mathrm{t}}\right.$-Ab, 40×). (B) No reactivity in the thyroid isthmus of a patient with MTC $\left(C_{\mathrm{t}}-\mathrm{Ab}, 40 \times\right)$. (C) Sparse and isolated $\mathrm{C}$ cells in the lateral thyroid lobe of a patient with benign nodular thyroid disease $\left(C_{\mathrm{t}}-\mathrm{Ab}, 40 \times\right)$. (D) No reactivity in the thyroid isthmus of a patient with benign nodular thyroid disease $\left(C_{\mathrm{t}}-\mathrm{Ab}, 40 \times\right)$.

\section{Discussion}

\section{General considerations}

To the best of our knowledge, this study represents the first work investigating the clinico-pathological characteristics of solitary nodules arising from the thyroid isthmus, and in particular their association with MTC.

\section{The thyroid isthmus and the parafollicular C cells}

In our series, we have not found either parafollicular $\mathrm{C}$ cells or $\mathrm{C}$ cell-derived tumors in the thyroid isthmi of patients with both benign NTD and MTC. To perform immunohistochemical investigations, we used antibodies against $C_{\mathrm{t}}$ because several studies have shown that this is the most effective method to detect parafollicular C cells $(16,17,22)$. During embryonic development, $\mathrm{C}$ cells migrate from the ventral parts of the fourth branchial pouch or the ultimobranchial bodies into the thyroid gland that descends caudally from the median anlage (23). Within the thyroid, C cells have a peculiar distribution. Indeed, autopsy studies conducted on normal thyroid glands in the 1970s and 1980 s, when specific anti- $C_{t}$ antibodies were not available yet (24), found that parafollicular C cells were distributed symmetrically in both lateral lobes, concentrated in a zone in the upper two-thirds of the lateral lobes bilaterally. When the isthmus was investigated, few scattered cells or even no cells were seen. Subsequently, studies using more accurate techniques for $C_{\mathrm{t}}$ immunostaining confirmed previous observations, failing to detect $\mathrm{C}$ cells in the thyroid isthmus of patients with $\mathrm{CCH}(15,16)$. $\mathrm{CCH}$ is defined as the presence of more than $50 \mathrm{C}$ cells in a single lowpower field $(\times 10$ magnification $)$ in both thyroid lobes (21), of solid nests of C cells with $>7$ cells per nest, or of follicles completely surrounded by $\mathrm{C}$ cells. Although the occurrence of $\mathrm{CCH}$ has been reported in patients with benign diseases (25), some authors consider $\mathrm{CCH}$ as a preneoplastic event, especially in patients with hereditary MTC. In the surgical series of Wahl et al. (19), the isthmi of 58 patients with both normal and elevated pre-operative serum $C_{t}$ concentrations (due to either $\mathrm{CCH}$ or MTC) were investigated by immunohistochemical studies; $C_{\mathrm{t}}$-positive cells were seen in none of them. The authors concluded that isthmus-preserving total bilobectomy removes all $\mathrm{C}$ cells and that total thyroidectomy is not necessary in patients with $\mathrm{CCH}$. Because of the few papers published in the literature on this topic and the small number of patients with FMTC included in our series, the possibility that patients with RET proto-oncogene germline mutations present with multifocal disease involving the isthmus cannot be definitively ruled out and should be investigated by further studies.

\section{The routine measurement of serum $\mathrm{C}_{t}$ concentrations in patients with solitary isthmic nodule}

MTC is a malignant tumor of the thyroid gland that appears as nodule(s) and represents $\sim 5 \%$ of all thyroid neoplasms $(3,26)$. MTC arises from the neural crestderived parafollicular $C$ cells (4), presents in the familial form with a genetic mutation in $25 \%$ of the cases $(1,5)$, and is the most aggressive of differentiated thyroid carcinomas, with a survival rate at 10 years approaching $40-50 \%$ and depending on the tumor stage at diagnosis $(3,27)$. In the literature, a convincing body of evidence exists showing that when the neoplasm is confined within the thyroid and thyroidectomy with dissection of the central lymph node compartment is performed, the chance of definitive cure is high $(3,10$, 28). Therefore, early detection of MTC is crucial to perform the best surgical approach before extrathyroidal dissemination and to save the patient's life.

Actually, two diagnostic tools are available for the evaluation of patients with NTD, including those with MTC: FNAC and measurement of human $C_{\mathrm{t}}$ concentrations. Previous European studies recruiting large series of patients with NTD (6-12) demonstrated that it is possible to diagnose MTC earlier with $C_{\mathrm{t}}$ screening than FNAC, particularly in patients with nodules smaller than $10 \mathrm{~mm}$ (microMTCs). Hence, the ETA has recommended $C_{\mathrm{t}}$ screening in all subjects with NTD (13). Although authors from the United States have also confirmed the European observations and even the costeffectiveness of $C_{\mathrm{t}}$ screening (14), as yet the ATA does not recommend it, mainly due to its high costs (15). 
At present, the recession of the world economy invariably affects the decisions of the Western governments on health policy. Thus, we do believe that, on the one hand and owing to actual evidence, $C_{t}$ screening should be performed in NTD patients and, on the other hand, the problem of cost deserves special consideration. In a recent study recruiting a large series of patients with NTD, we have identified a subgroup, i.e. subjects younger than 40 years, who should not be candidates to undergo the routine measurement of $C_{\mathrm{t}}$ because in these individuals (without a family history of MEN) we did not observe any cases of MTC. Now, based on the results of the present study, we propose that another patient subgroup, i.e. NTD subjects with solitary nodules of the thyroid isthmus, should not undergo $C_{\mathrm{t}}$ testing routinely. In Italy, the total cost of a single basal CT measurement averages $45 €$ In our 3-year prospective study, of 3978 patients referred with NTD to our institutions, no sporadic MTCs were disclosed in the 875 patients younger than 40 years (data not shown). The cost avoidance of not performing the $C_{\mathrm{t}}$ test in our patients aged $<40$ years and in those presenting with solitary isthmic nodules (1062 subjects altogether) would have saved $47790 €$ (about \$66 900).

\section{The thyroid isthmus and nonparafollicular C cell-derived tumors}

This is the first study investigating the clinicopathological characteristics of patients with solitary isthmic nodule. In our series, the prevalence of nodules located within the thyroid isthmus only was low with respect to the nodules located in the thyroid lateral lobes. Indeed, patients with a solitary isthmic nodule accounted for $6.4 \%$ of the whole NTD population recruited in the study. The female to male ratio of $\sim 4$ to 1 is similar to that found in previous NTD prevalence studies (29). Nonetheless, the mean and median age of our patient group -46.2 years and 49 years respectively - averages that reported in other NTD series (29).

However, our results have also demonstrated some differences compared to nonselected NTD populations recruited previously. For instance, in our series, a primary malignant neoplasm was found in $9 \%$ of the patients with solitary isthmic nodules. Previous studies $(30,31)$ have reported a frequency of cancer lower than $5 \%$ in subjects with NTD. Further prospective studies are needed to confirm whether subjects with solitary isthmic nodule truly present a higher risk of thyroid cancer than subjects with nodules located in the lateral lobes. Interestingly, in our series, almost all tumors were PTCs. Such data demonstrate that thyroid isthmic nodules behave as their lateral thyroid lobe counterparts. Indeed, since goiter prevention policy by iodine supplementation has become a priority in the western countries (in Italy, a specific law has been passed recently to make iodine salt supplementation mandatory), a decrease in the incidence of follicular thyroid carcinomas has been observed (32). On the other hand, an increase in the frequency of PTCs has been shown worldwide (33-35). This event is likely due to the thyroid nodule management effects after the nuclear Chernobyl accident, as reflected by the fact that half of PTCs in our series were microcarcinomas (36).

\section{Conclusions}

Lesions of the isthmus are significantly less likely to be MTC in patients who present with sporadic disease. Therefore, $C_{t}$ screening is not warranted in these subjects. Nonetheless, STIN are more likely to be neoplastic and deserve equal attention as those of the lateral lobes.

\section{Declaration of interest}

There is no conflict of interest that could be perceived as prejudicing the impartiality of the research reported.

\section{Funding}

This research did not receive any specific grant from any funding agency in the public, commercial, or not-for-profit sector.

\section{Acknowledgements}

The authors are deeply indebted to Prof. Sylvia L Asa, MD, PhD, Pathologist-in-Chief and Medical Director, Laboratory Medicine Program, University Health Network, University of Toronto, Canada, for her skilful comments and suggestions.

\section{References}

1 Hegedus L. Clinical practice: the thyroid nodule. New England Journal of Medicine 2004351 1764-1771.

2 Ezzat S, Sarti DA, Cain DR \& Braunstein GD. Thyroid incidentalomas. Prevalence by palpation and ultrasonography. Archives of Internal Medicine 1994154 1838-1840.

3 Kebebew E, Ituarte PHG, Siperstein AE, Duh QY \& Clark OH. Medullary thyroid carcinoma: clinical characteristics, treatment, prognostic factors, and a comparison of staging systems. Cancer 200088 1139-1148.

4 Ashworth M. The pathology of preclinical medullary thyroid carcinoma. Endocrine Pathology 200415 227-231.

5 Leboulleux S, Baudin E, Travagli JP \& Schlumberger M. Medullary thyroid carcinoma. Clinical Endocrinology $200461299-310$.

6 Pacini F, Fontanelli M, Fugazzola L, Elisei R, Romei C, Di Coscio G, Miccoli P \& Pinchera A. Routine measurement of serum calcitonin in nodular thyroid diseases allows the preoperative diagnosis of unsuspected sporadic medullary thyroid carcinoma. Journal of Clinical Endocrinology and Metabolism 199478 826-829.

7 Rieu M, Lame MC, Richard A, Lissak B, Sambort B, Vuong-Ngoc P, Berrod JL \& Fombeur JP. Prevalence of sporadic medullary thyroid carcinoma: the importance of routine measurement of serum calcitonin in the diagnostic evaluation of thyroid nodules. Clinical Endocrinology $1995 \mathbf{4 2} 453-460$.

8 Niccoli P, Wion-Barbot N, Caron P, Henry JF, de Micco C, Saint Andre JP, Bigorgne JC, Modigliani E \& Conte-Devolx B. Interest of 
routine measurement of serum calcitonin: study in a large series of thyroidectomized patients. The French Medullary Study Group. Journal of Clinical Endocrinology and Metabolism 199782 338-341.

9 Vierhapper H, Raber W, Bieglmayer C, Kaserer K, Weinhäusl A \& Niederle B. Routine measurement of plasma calcitonin in nodular thyroid diseases. Journal of Clinical Endocrinology and Metabolism 199785 1589-1593.

10 Elisei R, Bottici V, Luchetti F, Di Coscio G, Romei C, Grasso L, Miccoli P, Iacconi P, Basolo F, Pinchera A \& Pacini F. Impact of routine measurement of serum calcitonin on the diagnosis and outcome of medullary thyroid cancer: experience in 10864 patients with nodular thyroid disorders. Journal of Clinical Endocrinology and Metabolism 200489 163-168.

11 Vierhapper H, Niederle B, Bieglmayer C, Kaserer K \& BaumgartnerParzer I. Early diagnosis and curative therapy of medullary thyroid carcinoma by routine measurement of serum calcitonin in patients with thyroid disorders. Thyroid 200515 1267-1272.

12 Papi G, Corsello SM, Cioni K, Pizzini AM, Corrado S, Carapezzi C, Fadda G, Baldini A, Carani C, Pontecorvi A \& Roti E. Value of routine measurement of serum calcitonin concentrations in patients with nodular thyroid disease: a multicenter study. Journal of Endocrinological Investigation 200629 427-437.

13 Pacini F, Schlumberger M, Dralle H, Elisei R, Smit JWA \& Wiersinga W, European Thyroid Cancer Taskforce. European consensus for the management of patients with differentiated thyroid carcinoma of the follicular epithelium. European Journal of Endocrinology 2006154 787-803.

14 Cooper DS, Doherty GM, Haugen BR, Kloos RT, Lee SL, Mandel SJ, Mazzaferri E, McIver B, Sherman SI \& Tuttle RM, American Thyroid Assoociation Guideline Taskforce. Management guidelines for patients with thyroid nodules and differentiated thyroid cancer. Thyroid 200616 109-142.

15 American Thyroid Association Guidelines Task Force, Kloos RT, Eng C, Evans DB, Francis GL, Gagel RF, Gharib H, Moley JF, Pacini F, Ringel MD, Schlumberger M \& Wells SA Jr. Medullary thyroid cancer: management guidelines of the American Thyroid Association. Thyroid $200919565-612$.

16 Cheung K, Roman SA, Wang TS, Walker HD \& Sosa JA. Calcitonin measurement in the evaluation of thyroid nodules in the United States: a cost-effectiveness and decision analysis. Journal of Clinical Endocrinology and Metabolism 200893 2173-2180.

17 Biddinger PW, Brennan MF \& Rosen PP. Symptomatic C-cell hyperplasia associated with chronic lymphocytic thyroiditis. American Journal of Surgical Pathology 199115 599-604.

18 Guyétant S, Rousselet MC, Durigon M, Chappard D, Franc B, Guerin O \& Saint-André JP. Sex-related C cell hyperplasia in the normal human thyroid: a quantitative autopsy study. Journal of Clinical Endocrinology and Metabolism 199782 42-47.

19 Wahl RA, Vorländer C, Kriener S, Pedall J, Spitza M \& Hansmann ML. Isthmus-preserving total bilobectomy: an adequate operation for C-cell hyperplasia. World Journal of Surgery $200630860-871$.

20 Carcangiu ML. Section XI, Thyroid. In Histology for Pathologists, 3rd edn, ch 44, pp 1129-1148. Ed SE Mills. Philadelphia, USA: Lippincott Williams \& Wilkins, 1990.

21 Rosai J, Carcangiu ML \& DeLellis RA. Tumors of the Thyroid Gland, 3rd series, Fascicle 5, pp 223-229. AFIP, Armed Forces Institute of Pathology: Washington, DC 1990.

22 Schmid KW, Kirchmair R, Ladurner D, Fischer-Colbrie R \& Böcker W. Immunohistochemical comparison of chromogranins
A and B and secretogranin II with calcitonin and calcitonin generelated peptide expression in normal, hyperplastic and neoplastic C-cells of the human thyroid. Histopathology 199221 225-232.

23 Sadler TW \& Langman J. Medizinische embryologie die normale menschliche entwicklung und ihre fehlbildungen. Thieme 2003 10 330-335.

24 Wolfe HJ, Voelkel EF \& Tashjian AH. Distribution of calcitonincontaining cells in the normal adult human thyroid gland: a correlation of morphology with peptide content. Journal of Clinical Endocrinology and Metabolism 197438 688-694.

25 Guyetant S, Wion-Barbot N, Rousselet MC, Franc B, Bigorgne JC \& Saint-André JP. C-cell hyperplasia associated with chronic lymphocytic thyroiditis: a retrospective quantitative study of 112 cases. Human Pathology 199425 514-521.

26 Heshmati HM, Gharib H, van Heerden JA \& Sizemore GW. Advances and controversies in the diagnosis and management of medullary thyroid carcinoma. American Journal of Medicine 1997 $10360-69$.

27 Santoro M, Melillo RM, Carlomagno F, Vecchio G \& Fusco A. RET: normal and abnormal functions. Endocrinology 2004145 5448-5451.

28 Gharib H, McConahey WM, Tiegs RD, Bergstralh EJ, Goellner JR, Grant CS, van Heerden JA, Sizemore GW \& Hay ID. Medullary thyroid carcinoma: clinicopathologic features and long-term follow-up of 65 patients treated during 1946 through 1970. Mayo Clinic Proceedings 199267 934-940.

29 Fleming JB, Lee JE, Bouvet M, Schultz PN, Sherman SI, Sellin RV, Friend KE, Burgess MA, Cote GJ, Gagel RF \& Evans DB. Surgical strategy for the treatment of medullary thyroid carcinoma. Annals of Surgery 1999230 697-707.

30 Tan GH \& Gharib H. Thyroid incidentalomas; management approaches to nonpalpable nodules discovered incidentally on thyroid imaging. Annals of Internal Medicine 1997126 226-231.

31 Filetti S, Durante C \& Torlontano M. Nonsurgical approaches to the management of thyroid nodules. Nature Clinical Practice. Endocrinology \& Metabolism 20062 384-394.

32 Kondo T, Ezzat S \& Asa SL. Pathogenetic mechanisms in thyroid follicular-cell neoplasia. Nature Reviews. Cancer 20066 292-306.

33 Burgess JR \& Tucker P. Incidence trends for papillary thyroid carcinoma and their correlation with thyroid surgery and thyroid fine-needle aspirate cytology. Thyroid 200616 47-53.

34 Colonna M, Guizard AV, Schvartz C, Velten M, Raverdy N, Molinie F, Delafosse P, Franc B \& Grosclaude P. A time trend analysis of papillary and follicular cancers as a function of tumour size: a study of data from six cancer registries in France (1983-2000). European Journal of Cancer 2007 43 891-900.

35 Enewold L, Zhu K, Ron E, Marrogi AJ, Stojadinovic A, Peoples GE \& Devesa SS. Rising thyroid cancer incidence in the United States by demographic and tumor characteristics, 1980-2005. Cancer Epidemiology, Biomarkers and Prevention 200918 784-791.

36 Leenhardt L, Grosclaude P \& Cherie-Challine L, Thyroid Cancer Committee. Increased incidence of thyroid carcinoma in France: a true epidemic or thyroid nodule management effects? Report from the French Thyroid Cancer Committee Thyroid 200414 1056-1060.

Received 28 August 2009

Accepted 29 September 2009 